\title{
Antibacterial polyurethanes, modified with cinnamaldehyde, as potential materials for fabrication of wound dressings
}

\author{
J. Kucinska-Lipka ${ }^{1} \cdot$ I. Gubanska ${ }^{1}$ A. Lewandowska ${ }^{1} \cdot$ A. Terebieniec ${ }^{2}$. \\ A. Przybytek ${ }^{1} \cdot$ H. Cieśliński ${ }^{2}$
}

Received: 1 February 2018 / Revised: 6 August 2018 / Accepted: 7 September 2018 /

Published online: 14 September 2018

(c) The Author(s) 2018

\begin{abstract}
The epidermis is a skin layer, which protects an organism from the different factors of external environment. Therefore, the fast and effective regeneration of epidermis is important. Potential materials used for epidermis regeneration may be polyurethane scaffolds in form of the thin permeable layers. One and main disadvantage of such polyurethane scaffolds are their lack of antibacterial and antifungal properties. The great proposition to improve antiseptic properties of polyurethane epidermis scaffolds is to modify them with the use of substances, which reveal antiseptic, antimicrobial, and/or antifungal properties like cinnamaldehyde (CA). The great advantage speaking in favor of this compound is the fact that it has been approved and concerned as generally safe by the Food and Drug Administration in the USA. In this paper was described the fabrication of antibacterial microporous polyurethane scaffolds (MPTLs) in a form of a thin layers by using solvent-casting/particulateleaching technique combined with thermally induced phase separation. Obtained MPTLs were modified with CA at different concentrations (0.5-5\%): to establish the most suitable antibacterial effect of the CA introduced into the MPTLs matrix. Obtained unmodified and CA-modified MPTLs were characterized by mechanical and physicochemical properties as well as by identification of their antibacterial performance. The performed studies revealed that the most relevant antimicrobial effect of CA-modified MPTLs was observed when the CA concentration was $3.5 \%$.
\end{abstract}

Keywords Epidermis regeneration - Cinnamaldehyde $\cdot$ Microporous polyurethane thin-layer scaffolds $\cdot$ Antibacterial properties $\cdot$ Tissue engineering

J. Kucinska-Lipka

juskucin@pg.gda.pl

1 Polymer Technology Department, Chemical Faculty, Gdansk University of Technology (GUT), Narutowicza Street 11/12, 80-232 Gdansk, Poland

2 Molecular Biotechnology and Microbiology Department, Chemical Faculty, Gdansk University of Technology (GUT), Narutowicza Street 11/12, 80-232 Gdansk, Poland 


\section{Introduction}

People have been struggling with injuries and damages of skin epidermis caused by burns, which took place through contact with a hot water, sun, chemicals, flames, but also it can be a result of diseases [1]. Inappropriately treated wounds can cause infections or even death. Therefore, when the damages of epidermis are deep and the tissue cannot be naturally restored, it is important to use materials, which will support and assist in epidermis regeneration. The materials used as a dressing have to be characterized by the ability of bacterial growth inhibition [2], effective absorption of the wound exudates [3], ensure suitable wound humidity [4], enable formation of new tissue with no scars [5], and be permeable for gases and delivery of nutrients [6].

By the long time, to heal damages of skin only cotton dressings were used. Recently, it has changed. Now, humans have a wide access to the dressings from other materials such as: chitosan [7], gelatin [8], poly(vinyl alcohol) [9], silk [10], alginates [11], and their blends or composites [12]. Only the biomaterials for wound dressings can have a variety of forms: foam, films, hydrogels, fibers [13, 14].

Currently, researchers are working on hydrogel dressings, due to the fact that hydrogels meet strict requirements for biomedical applications. Moreover, the structure of hydrogels allows the attachment of drugs, healing factors, and also analgesics. On the other hand, hydrogel dressings have one main disadvantage such as lack of ability to control the degradation process of these materials. According to this, other types of materials are being studied, for example, polyurethanes (PUR).

Currently, commercial PUR wound dressings are already on the market: Tegaderm [15], Bioclusive [16]. However, these materials do not have ideal properties [13]. Due to this fact, researchers are working on the application of modified PUR materials for wounds healing. Lin et al. [17] described the preparation of PUR/ hydrogel composites which contain fibroblast cells. Hydrogel was prepared from aqueous solution of nano-clay, $\mathrm{N}$-isopropyl acrylamide, and acrylic acid monomers which were exposed to gamma radiation. Such PUR/hydrogel material provided moist environment for wound healing and minimizes a possibility creation of scars. Oh et al. [18] obtained foamed PUR materials for wound healing, which were coated with alginate/bentonite hydrogel. Such composite wound dressings occurred to be functional materials in terms of skin regeneration. Manikandan et al. fabricated PUR/murivenna oil nanocomposite wound dressing through electrospinning method, in the form of nanofibrous mats. Previous studies confirmed that these materials possess most of the properties relevant in wound-healing process. What is worth to underline is the fact that these PUR/murivenna oil nanofibrous scaffolds, in performed blood compatibility assay (according to ASTMF756-00(2000) standard), occurred to be non-hemolytic materials [19], thus suitable for epidermis regeneration.

In summary, PUR possess a great possibility to tune their properties to keep them biocompatible [20], non-toxic [21], and of suitable mechanical characteristic. Degradation rate of PURs can be controlled as well, by proper design of the raw materials used for their synthesis [22]. This is rather impossible in the 
case of other biomaterials dedicated for medical field. What is interesting, is the fact that by using PUR materials it is possible to obtain porous tissue scaffolds, which will have structure similar to the structure of epidermis and will possess a proper parameters for skin regeneration, if a proper technique of their fabrication will be applied. In the literature are described a variety of PUR scaffolds fabrication methods such as: solvent casting with salt leaching (SC/SL) [23], thermally induced phase separation (TIPS) [24], electrospinning [25], and more recently the $3 \mathrm{D}$ printing [26]. One of the most important features of the scaffold for epidermis regeneration is its suitable thickness, which should be between 0.05 and $1.5 \mathrm{~mm}$ [27]. Such dimensions can be obtained while using SC/PL technique combined with TIPS, what was described in our previous work [28].

The other issue to be solved, in terms of PUR scaffolds for wound healing, is their not sufficient antimicrobial and antifungal effect [29]. However, as it was mentioned previously, PUR due to its structure can be easily tailored in terms of their properties, and the additional modifications are possible. One of such modifications can be application of CA. The CA, in other words cynamal, is the yellow liquid with intensive and sweet-spicy flavor, belonging to the group of aromatic aldehydes [30]. The CA is the main component of cinnamon oil, natural compound extracted from cinnamon leaf and bark [31]. The main content of CA is oil of Cinnamomum zeylanicum tree. CA exhibits antibacterial, antifungal, and antiinflammatory properties [32], which may be very useful for wound healing. The fact that CA contains an aldehyde groups indicates that it can be included into the chemical structure of such polymers as polyurethanes, chitosan, polylactide, cellulose, or alginates. The CA has been accepted by the World Health Organization as a food-flavoring agent and has been approved as generally safe by the Food and Drug Administration [33]. References reports the information, which confirms antiseptic properties of CA, and among others, CA revealed antimicrobial activity against Pseudomonas syringae pv. actinidiae (plant pathogen) [34], Escherichia coli, and Salmonella sp [35]. Importantly, in relation to the presented research, CA after incorporation into cellulose-based package film also revealed antimicrobial activity against 10 spoilage and pathogenic bacteria: Aeromonas hydrophila, Bacillus cereus, E. coli DMST 4212, E. coli O157: H7, Listeria monocytogenes, Micrococcus luteus, Pseudomonas aeruginosa, Salmonella enteritidis, Staphylococcus aureus, Enterococcus faecalis, and antifungal activity against three yeasts Candida albicans, Saccharomyces cerevisiae, and Zygosaccharomyces rouxii [36]. Mechanism of antimicrobial activity of CA depends on its concentration. In general, trans-cinnamaldehyde can inhibit growth of E. coli and S. typhimurium without disintegrating the outer membrane of bacterial cell or depleting intracellular ATP. At low concentrations, it inhibits enzymes involved in cytokine interactions or other less important cell functions. When the concentration is higher, it inhibits ATPase, and at lethal amounts, cinnamaldehyde perturbs the cell membrane [37].

Moreover, other studies also revealed an inhibitory effect of CA on microbial biofilm formation [38, 39]. In this form, bacteria exhibit elevated resistance to a host defense system and also antibiotics activities, which often results in difficult-to-treat infections [39]. The researchers showed that the cinnamaldehyde effectively reduces 
the amount of bacterial cells [35]. In addition, Dewi et al. [40] revealed by studies on fabricated hydrogels modified with cinnamaldehyde (concentrations were $4 \%$, $6 \%, 8 \%, 10 \%$ ) that cinnamaldehyde for all concentrations was non-toxic for the cells.

However, in the literature, there can be found also other variants such as: natural antiseptic modifiers (plant extracts), for example, thyme and jambolan which could be used as a potential antibacterial and antifungal agent against $P$. aeruginosa and $S$. aureus, respectively [41]. The other examples of compounds with antibacterial properties were described by Brostow et al. [42] and Barbakadze et al. [43].

In this paper, we described the modification of microporous polyurethane thinlayer scaffolds (MPTLs) with CA performed at different concentrations $(0.5 \% ; 1 \%$; $2 \% ; 3.5 \%$, and $5 \%$ ). CA was chosen according to its antibacterial and antifungal properties. The concentration rage was established according to the literature reports mentioned already in the introduction. MPTLs were obtained by using SC/PL technique combined with TIPS as it was described in our previously published article [28]. Obtained unmodified and CA-modified MPTLs were characterized by their mechanical properties, morphology, and microbiological performance. According to the performed studies, the optimal antibacterial effect was observed when $3.5 \%$ of CA was used. Thus, such CA-modified MPTLs may find an application in the field of regenerative medicine of skin.

\section{Materials}

MPTLs used in this study were fabricated by using poly(ester urethane) s synthesized in our laboratory [44] with the use of raw materials: amorphous $\alpha$, $\omega$-dihydroxy(ethylene-butylene adipate) (POLIOS 55/20, Purinova, Poland), cycloaliphatic 4,4'-methylenebis(cyclohexyl isocyanate) (HMDI, Sigma Aldrich, Poland), 1,4-butanediol (BDO, Purinova, Poland), 1,4-dioxane, and n-hexane supplied by POCH (Poland). The sodium chloride was obtained from Culineo (France).

Bacterial strains-E. coli and S. aureus-used in this study was derived from a microbial culture collection of Department of Molecular Biotechnology and Microbiology (Gdansk University of Technology).

\section{Fabrication of unmodified MPTL scaffolds}

The detailed description of MPTLs fabrication is given in our previous paper [28]. Briefly poly(ester urethane) was dissolved in the 1,4-dioxane at the concentration of $20 \%$ wt. Solution of PUR was mixed with sodium chloride and transferred into the refrigerator $\left(-20^{\circ} \mathrm{C}\right)$ overnight. After that time samples were placed in the water bath to remove sodium chloride crystals. At the final step, MPTL samples were dried at room temperature for 3 days and then sterilized by using 70\% ethanol and UV light. The image of prepared MPTL is given in Fig. 1. 


\section{Fabrication of CA-modified MPTL scaffold}

The basic MPTL for further CA modification was fabricated as previously described. Then, basic MPTL was cut into $1.5-\mathrm{cm}^{2}$ samples and placed in the wells of the cell-culturing plates (24 well). Each sample was then immersed in $1 \mathrm{ml}$ of CA solution differing at concentrations $(0.5 \% ; 1 \% ; 2.5 \% ; 3.5 \% ; 5 \%)$ overnight and dried at room temperature for $24 \mathrm{~h}$. The CA-modified samples were sterilized by using 70\% ethanol and UV lamp. CA-modified MPTL samples prepared as described were further used for studies. The amount of CA used in the studies was established according to the literature reports [40].

\section{Methods}

\section{Fourier transform infrared specroscopy (FTIR)}

The FTIR measurements were carried out at Perkin-Elmer Frontier MIR/FIR spectrometer with TGS detector. Spectral range was between 600 and $4000 \mathrm{~cm}^{-1}$, of resolution $4 \mathrm{~cm}^{-1}$ and 254 scans.

\section{Microbiological tests}

Antibacterial activities of the prepared materials were tested by using E. coli (Gram negative) and $S$. aureus (Gram positive). All experiments were carried out

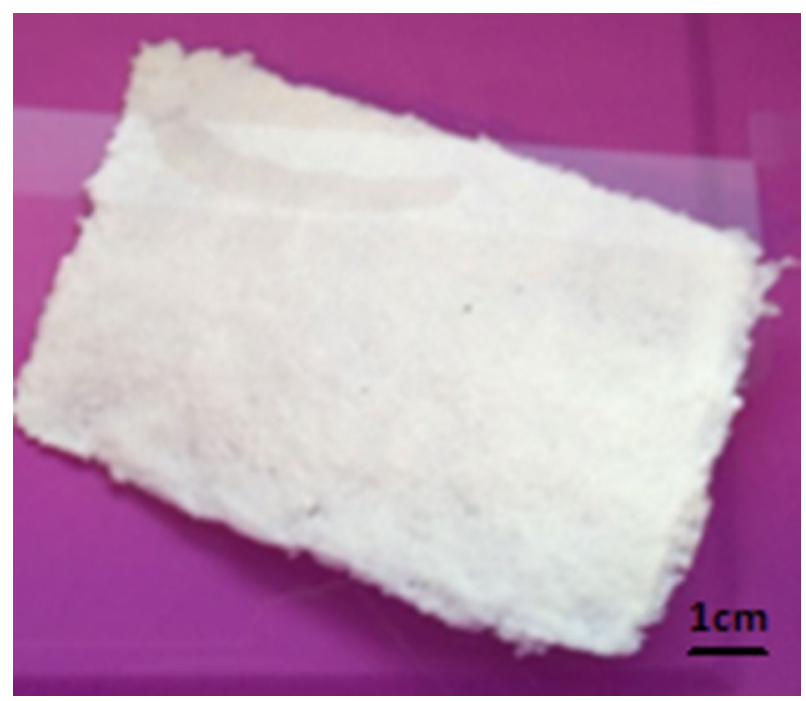

Fig. 1 Microporous polyurethane thin layers scaffold 
with use of the same bacterial strains, obtained from collection of the Department of Molecular Biotechnology and Microbiology, Gdańsk University of Technology. Stock cultures were maintained by periodic subculture on nutrient agar slants which were stored at $4{ }^{\circ} \mathrm{C}$. Before each experiment, strains were cultivated on fresh LA plates and incubated for $24 \mathrm{~h}$ at $37^{\circ} \mathrm{C}$. For preparation of LA plates, LA medium containing g/L: casein peptone 10.0; yeast extract 5.0; $\mathrm{NaCl} 10.0$, agar 15.0, was dissolved in $1 \mathrm{~L}$ of deionized water and then autoclaved $\left(121^{\circ} \mathrm{C}\right.$, $1.5 \mathrm{~atm} ., 20 \mathrm{~min}$ ), cooled to $45^{\circ} \mathrm{C}$, and poured into sterile Petri plates. Approximately $25 \mathrm{~mL}$ of sterile agar medium was poured into $90-\mathrm{mm}$ disposable, sterile Petri dishes and allowed to solidify. All reagents were supplied by BTL Sp. z o.o., Lodz. Poland.

The startup of the experiments was obtained by inoculating $20 \mathrm{~mL}$ of sterile LB (Luria Broth) with microbial strains from LA plates. Cultivation was carried out in 200-mL Erlenmeyer flasks, on a rotary shaker at $170 \mathrm{rpm}$ at $37^{\circ} \mathrm{C}$ for $24 \mathrm{~h}$. LB medium containing, g/L: casein peptone 10.0; yeast extract 5.0; $\mathrm{NaCl} 10.0$, was dissolved in $1 \mathrm{~L}$ of deionized water and then autoclaved $\left(121^{\circ} \mathrm{C}, 1.5 \mathrm{~atm}\right.$., $20 \mathrm{~min}$ ) and cooled to room temperature. All reagents were supplied by BTL Sp. z o.o., Lodz. Poland.

After the incubation, $1 \mathrm{~mL}$ of each bacterial strain suspension was transferred into $100-\mathrm{mL}$ sterile Erlenmeyer flasks containing $10 \mathrm{~mL}$ of the fresh LB medium. The cells were cultivated for $6-8 \mathrm{~h}$ at $37^{\circ} \mathrm{C}$ on a rotary shaker at $170 \mathrm{rpm}$ to get the $\log$ phase of bacteria. For determination of potential antibacterial activities of selected MPTLs, $100 \mu \mathrm{L}$ of each bacterial strain suspension were transferred and spread on LA plates with sterile glass rod. After of incubation of bacterial cultures on LA plates for $24 \mathrm{~h}$ at $37{ }^{\circ} \mathrm{C}$, the sterile samples of examined MPTL scaffolds were placed over the bacterial cultures on LA plates. For this purpose, samples surface (1 cm diameter) were sterilized by submerging in $70 \%$ ethanol and then rinsed thoroughly with sterile deionized water. Afterward, each side of PUR was exposed to UV radiation for $30 \mathrm{~min}$. Sterile samples were dried out in Thermobalance (RADWAG MAX50/SX) set at $80{ }^{\circ} \mathrm{C}$ for $30 \mathrm{~min}$ and then placed with sterile tweezers on LA plates. Plates were incubated in $37{ }^{\circ} \mathrm{C}$ for $24 \mathrm{~h}$. After the incubation, the presence or absence of zones of bacterial growth inhibition around samples of unmodified and modified MPTLs was checked [44].

\section{Mechanical properties}

Mechanical properties such as tensile strength $\left(T_{\mathrm{Sb}}\right)$, elongation at break $(\varepsilon \mathrm{b})$, Young's modulus (E) were characterized using a Zwick Roell Z020 testing machine according to PN-EN-ISO 1799:2009 at a crosshead speed of 50 $\pm 50 \mathrm{~mm} /$ min. The measurement was performed at room temperature. Six specimens of unmodified and of CA-modified MPTLs were tested, and the average values of $T_{\mathrm{Sb}}, \varepsilon \mathrm{b}$, and $E$ are given in Table 2 . 


\section{Scanning electron microscopy (SEM)}

The microstructure of unmodified and of CA-modified MPTLs was analyzed with the use scanning electron microscopy (Zeiss EVO-40) at an accelerating voltage of $20 \mathrm{kV}$. Before SEM study, the samples were sputter-coated with a thin layer of gold. For analyzing porosity and pores size of scaffolds was used Image J software (U.S. National Institutes of Health, Bethesda, MA, USA). The average pore size was obtained by measuring the diameter of 100 pores chosen randomly throughout the central section of the samples. To perform statistical analysis of pore size, we used Shapiro-Wilk test $(p<0.05)$ to determine normal distribution of the data, and to determine the average pore size, we used normal Gaussian-Lorentz distribution analysis.

\section{Water contact angle}

Water contact angle of materials was measured at room temperature by using Kruss Goniometer G10 (Germany) with drop-shape analysis software. Contact angle of 10 samples was evaluated by static contact angle measurements using the sessile drop method [45].

\section{Interactions with phosphate-buffered saline}

The interaction of unmodified and CA-modified scaffolds with phosphate-buffered saline (PBS) was studied. For this study, six samples of $1.5 \mathrm{~cm}^{3}$ were used. Samples were dried and weighted by using Thermobalance (RADWAG MAX50/SX) set at $60{ }^{\circ} \mathrm{C}$. Then, unmodified and CA-modified samples were transferred to the cell-culturing plate and immersed in $3 \mathrm{ml}$ of PBS. Mass changes were studied $24 \mathrm{~h}$, 7 days, and 1 month as follows: The samples were placed between paper towels in order to reduce the excess of PBS. In the next step, the samples were placed in Thermobalance (set at $60{ }^{\circ} \mathrm{C}$ ) and weighted to the constant mass. Measurements were performed at $37^{\circ} \mathrm{C}$. The weight loss was calculated by following Eq. (1):

$$
S=\left(\frac{m_{\mathrm{i}}-m_{0}}{m_{0}}\right) \cdot 100 \%
$$

where $m_{1}$ is sample weight after 1 st, 7 days, and 1 month of incubation $(g), m_{0}$ is sample weight before the test $(g)$. The results are arithmetic average of four measurements. Additionally, $\mathrm{pH}$ solution of PBS was controlled every 2 weeks with the use of Mettler Toledo $\mathrm{pH}$ meter. 
Fig. 2 Cinnamaldehyde chemical structure [40]
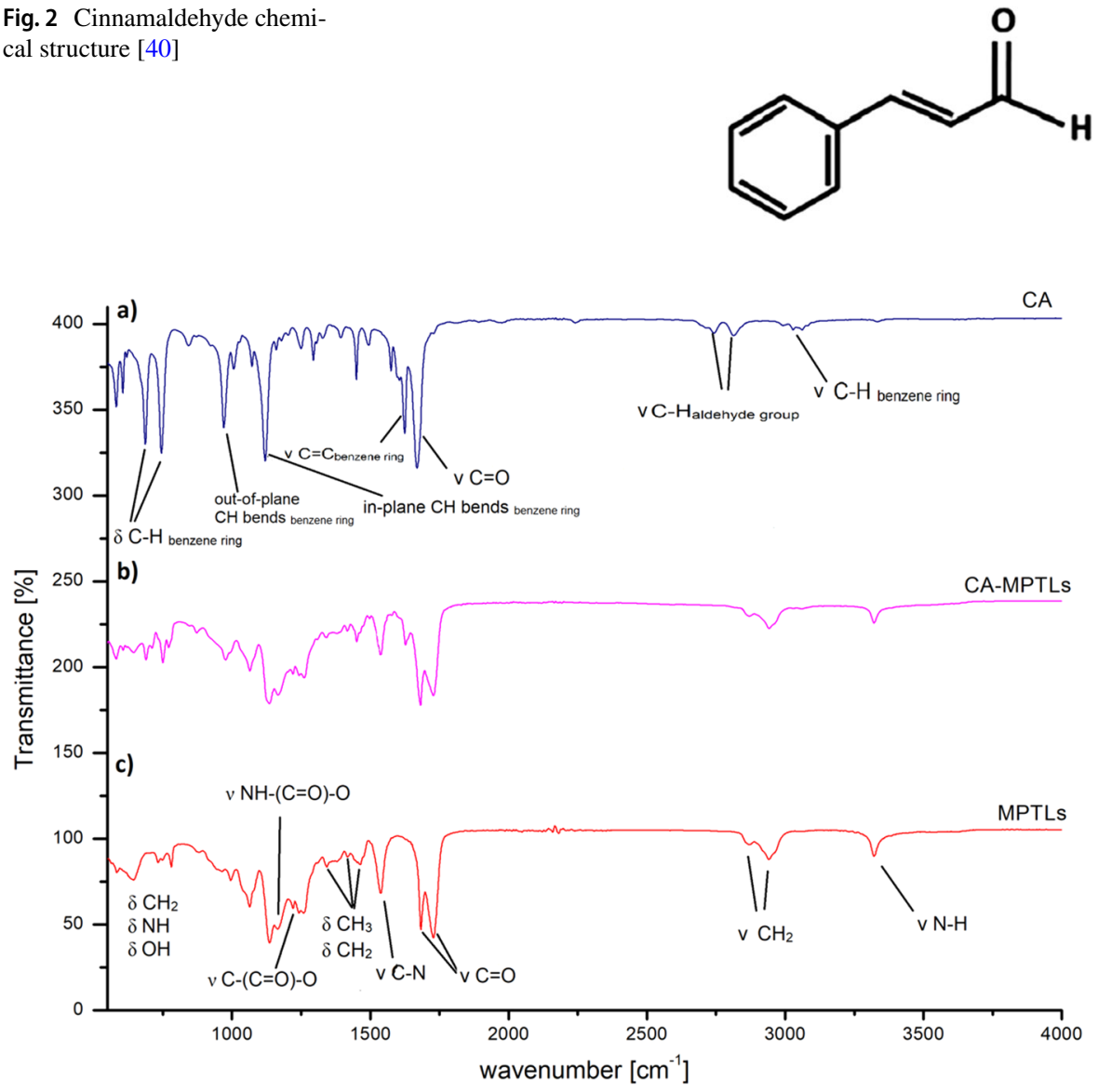

Fig. 3 FTIR spectra of a CA, b CA-modified MPTLs and $\mathbf{c}$ MPTLs

\section{Results}

\section{Fourier transform infrared specroscopy (FTIR)}

For easier analysis, FTIR spectra of CA and its structure are given in Fig. 2.

Figure 3 presents the FTIR spectra of CA, CA-modified MPTLs, and MPTLs. For the MPTLs, the main peaks: $3320 \mathrm{~cm}^{-1}$ (NH stretching vibration in urethane groups), 2940 and $2870 \mathrm{~cm}^{-1}\left(\mathrm{CH}_{2}\right.$ stretching vibration), 1728 and $1680 \mathrm{~cm}^{-1}(\mathrm{C}=\mathrm{O}$ stretching vibration, which not formed and formed hydrogen bond, respectively) $1537 \mathrm{~cm}^{-1}$ (CN stretching vibration), $1344-1460 \mathrm{~cm}^{-1}\left(\mathrm{CH}_{2}\right.$ deformation vibration), $1221-1260 \mathrm{~cm}^{-1}(\mathrm{C}-(\mathrm{C}=\mathrm{O})-\mathrm{O}$ stretching vibration, not hydrogen bonded $)$, $1166 \mathrm{~cm}^{-1}\left(\mathrm{NH}-(\mathrm{C}=\mathrm{O})-\mathrm{O}\right.$ stretching vibration), $995-1135 \mathrm{~cm}^{-1}(\mathrm{C}-(\mathrm{C}=\mathrm{O})-\mathrm{O}$ stretching vibration, hydrogen bonded), are visible [46, 47], whereas for CA, the spectra shows following bands $3028 \mathrm{~cm}^{-1}(\mathrm{CH}$ stretching vibration in attributed 
to ring of benzene), 2812 and $2742 \mathrm{~cm}^{-1}$ ( $\mathrm{CH}$ stretching vibration in the aldehyde group), $1669 \mathrm{~cm}^{-1}$ (C=O stretching vibration), $1624 \mathrm{~cm}^{-1}(\mathrm{C}=\mathrm{C}$ stretching vibration ascribed to ring of benzene), 1120 and $970 \mathrm{~cm}^{-1}$ (in-plane and out-of-plane $\mathrm{CH}$ bending vibration in benzene ring, respectively), 745 and $690 \mathrm{~cm}^{-1}$ (CH deformation vibration present in aromatic ring, position reveals that its monosubstituted benzene ring) [48-52].

Some of differences in the spectra of unmodified MPTLs and CA-modified MPTLs are observed in the range of $690-1200 \mathrm{~cm}^{-1}$ and $1600-1700 \mathrm{~cm}^{-1}$.

\section{Microbiological tests}

Figure 4 illustrates inhibition zones of bacterial growth detected when unmodified and CA-modified MPTLs had contact with selected bacterial species. A significant influence of CA on bacteria $E$. coli and $S$. aureus was observed when CA was used at higher concentration equal to $2.5 \% ; 3.5$, and $5 \%$. For unmodified MPTLs, the inhibition zones of bacteria were not observed. The most suitable antibacterial properties were observed for CA-modified MPTL at the CA concentration equal to $3.5 \%$

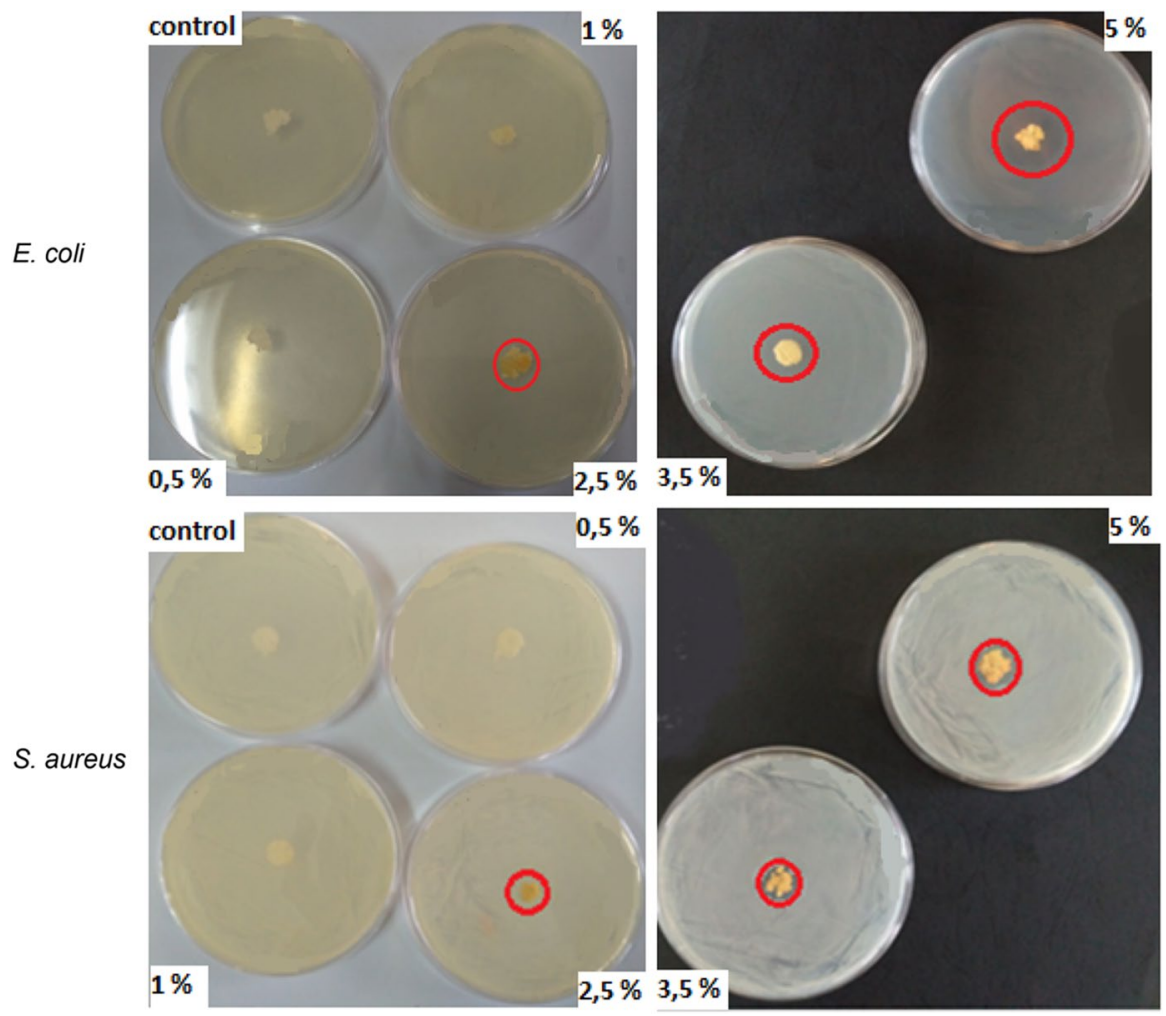

Fig. 4 Inhibition zones of studied bacterial species growth 
Table 1 Dimension of inhibition zones of selected bacterial species growth

\begin{tabular}{lll}
\hline Concentration of CA (\%) & $\begin{array}{l}\text { Areas of bacterial growth inhibition } \\
(\mathrm{mm})\end{array}$ \\
\cline { 2 - 3 } & E. coli & S. aureus \\
\hline 0.5 & 0 & 0 \\
1 & 0 & 0 \\
2.5 & $1 \pm 1$ & $1 \pm 1$ \\
3.5 & $4 \pm 1$ & $2 \pm 1$ \\
5 & $8 \pm 1$ & $4 \pm 1$ \\
\hline
\end{tabular}

Table 2 Tensile strength $\left(T_{\mathrm{SB}}\right)$, elongation at break $(\varepsilon)$ and Young's modulus $(E)$ of unmodified and of CA-modified MPTL scaffold

\begin{tabular}{llll}
\hline Sample & $T_{\mathrm{SB}}(\mathrm{MPa})$ & $\varepsilon(\%)$ & $E(\mathrm{MPa})$ \\
\hline MPTLs & $0.32 \pm 0.01$ & $78 \pm 6$ & $0.254 \pm 0.15$ \\
CA-MPTLs & $0.18 \pm 0.02$ & $68 \pm 4$ & $0.244 \pm 0.09$ \\
\hline
\end{tabular}

(Table 1). Thus, further characterization of CA-modified MPTLs was performed with the use of these materials.

\section{Mechanical properties}

In Table 2, tensile strength $\left(T_{\mathrm{Sb}}\right)$, elongation at break $(\varepsilon \mathrm{b})$, and Young's modulus $(E)$ were given. Unmodified MPTLs possessed $T_{\mathrm{Sb}}$ of $0.32 \pm 0.01 \mathrm{MPa}, \varepsilon \mathrm{b}$ of $78 \pm 6 \%$, and $\mathrm{E}$ of $0.254 \pm 0.15 \mathrm{MPa}$. Modification with CA only slightly influenced the mechanical properties of CA-modified MPTLs. The $T_{\mathrm{Sb}}, \varepsilon \mathrm{b}$, and $E$ of CA-modified MPTLs decreased to $0.18 \pm 0.02 \mathrm{MPa}, 68 \pm 4 \%, 0.244 \pm 0.09 \mathrm{MPa}$, respectively. Studied mechanical properties are in the range of mechanical requirements for soft tissues regeneration.

\section{Scanning electron microscopy}

The morphology images of unmodified and CA-modified MPTLs are shown in Fig. 5. Pore sizes of unmodified MPTLs were in the range of $65-426 \mu \mathrm{m}$, and their porosity was about $82 \%$. Comparative analysis of MPTLs and CA-modified MPTLs morphology performed by SEM showed that the CA-modified MPTLs revealed decrease in global porosity and increase in wall thickness in comparison with MPTLs. This could be an effect of pores closing by the presence of CA in the MPTLs structure. Both materials, unmodified MPTL (Fig. 5a) and CA-modified MPTL (Fig. 5b), are represented interconnected pores suitable for tissue engineering applications. Some micropores of the size $\sim 10 \mu \mathrm{m}$ were distinguished as well. 
Fig. 5 SEM images of a unmodified and $\mathbf{b}$ CA-modified MPTLS

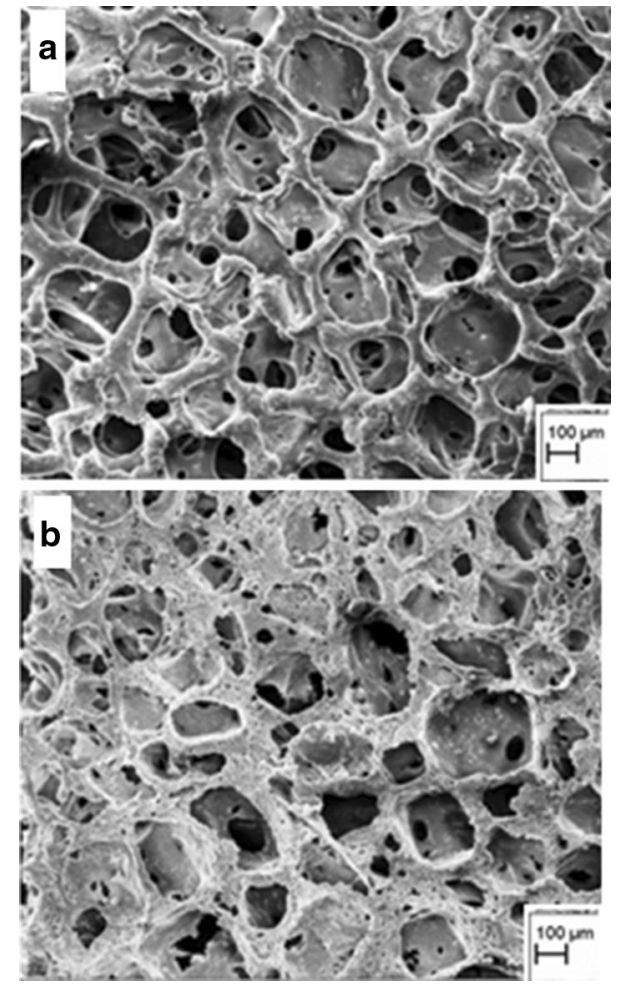

\section{Water contact angle}

Water contact angle of unmodified MPTLs was equal $54^{\circ} \pm 4^{\circ}$. The modification with CA of MPTLs caused increase in contact angle of about $12^{\circ}$, in comparison with unmodified MPTLs (Table 3). The CA has a hydrophobic character [53], and therefore its presence in MPTLs increased their contact angle, which was till in the reference range for biomedical applications and proper cells adhesion $\left(45^{\circ}-76^{\circ}\right)$.

\section{Interactions with phosphate-buffered saline}

Mass change of the unmodified and CA-modified MPTLs after $24 \mathrm{~h}, 7$ days, and 1 month of incubation in PBS is given in Table 4. After $24 \mathrm{~h}$ and 7 days, the mass

Table 3 Water contact angle of unmodified and CA-modified MPTL scaffold

\begin{tabular}{ll}
\hline Sample & $\begin{array}{l}\text { Water contact } \\
\text { angle (aver- } \\
\left.\text { age } \pm \mathrm{SD}^{\circ}\right)\end{array}$ \\
\hline MPTLs & $54 \pm 4$ \\
CA-MPTLs & $66 \pm 2$ \\
\hline
\end{tabular}


Table 4 Weight loss of unmodified and modified MPTL scaffolds in PBS

\begin{tabular}{llcc}
\hline Sample & \multicolumn{2}{l}{ Weight loss $(\%)$} & \\
\cline { 2 - 4 } & 1 day & 7 days & 1 month \\
\hline MPTLs & $0.2 \pm 0.1$ & $8 \pm 1$ & $50 \pm 1$ \\
CA-MPTLs & $0.4 \pm 0.1$ & $10 \pm 2$ & $63 \pm 2$ \\
\hline
\end{tabular}

change was not significant (up to $10 \%$ for CA-modified MPTLs, Table 4). After 1 month, mass of unmodified and CA-modified MPTLs decreased rapidly in a significant percentage of $50 \%$ for unmodified MPTLs and $63 \%$ for CA-modified MPTLs.

The morphological changes of unmodified and CA-modified MPTLs before and after degradation process are shown in Fig. 6. After degradation process, pores of unmodified and CA-modified MPTLs looked differently in comparison with the morphology before the degradation (Fig. 6b,d). They were more irregular in shape, and the edges were more ragged. It can be related to the defragmentation of MPTLs.
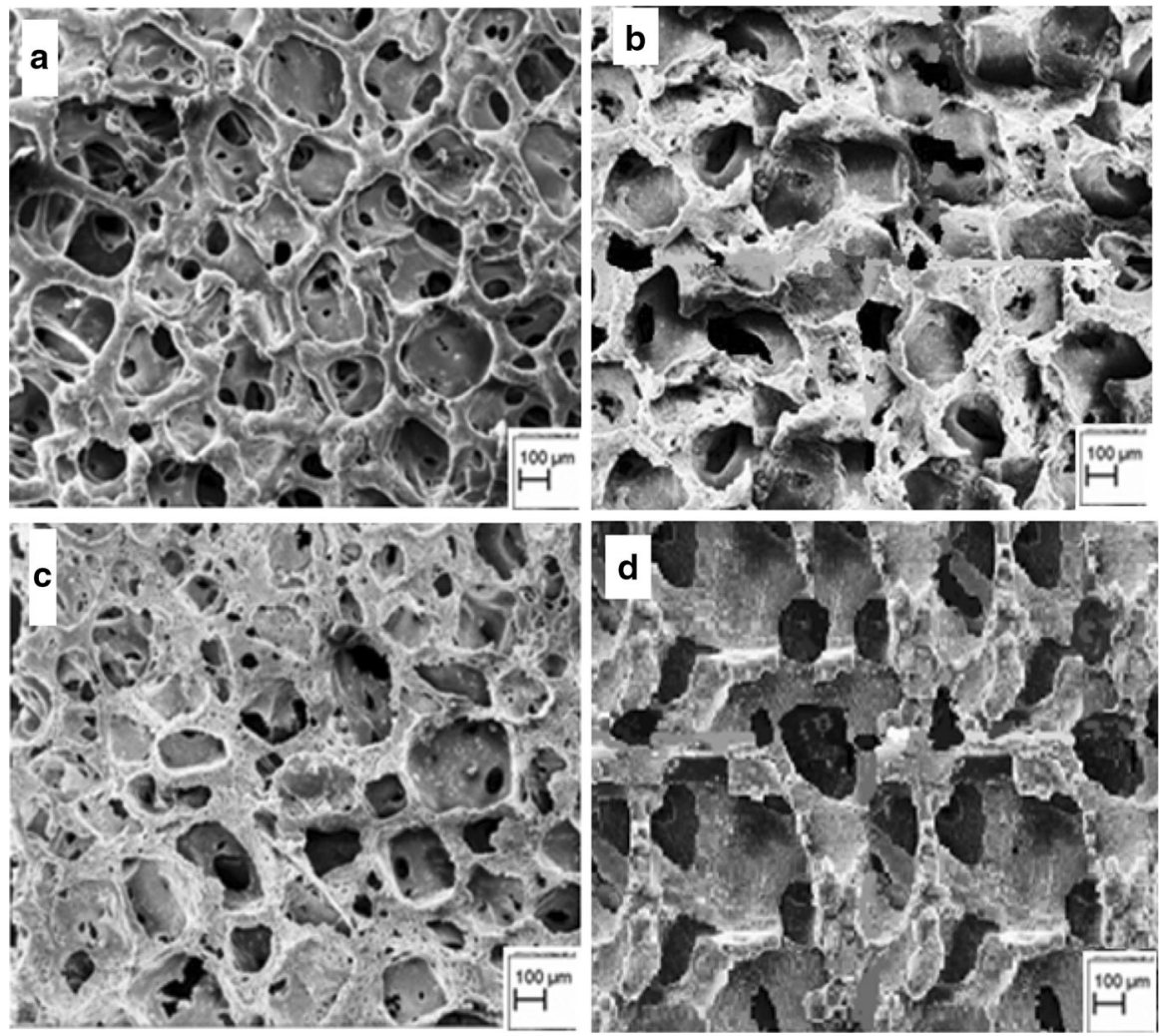

Fig. 6 SEM images of MPTLs a before, $\mathbf{b}$ after degradation and CA-MPTLs $\mathbf{c}$ before, $\mathbf{d}$ after 1 month of incubation in PBS 
Thus, it may be an evidence that unmodified and CA-modified MPTLs may undergo degradation in the environment of body fluids.

\section{Discussion}

One of the developed solutions in the field of tissue engineering is to find a biocompatible, antibacterial, and of proper mechanical properties biomaterial, which could be used as epidermal scaffold. Therefore, this work describes a fabrication of MPTLs by using SC/PL technique combined with TIPS and their modification with CA to improve the antimicrobial performance of such scaffolds, which could be used in the field of skin regeneration.

In order to confirm the effective CA modification the FTIR study was performed. Spectra analysis of MPTLs and CA-modified MPTLs indicated some differences in the spectral range $690-1200 \mathrm{~cm}^{-1}$ and $1600-1700 \mathrm{~cm}^{-1}$; this could be related to the presence of the benzene ring, aldehyde group of CA, and formation of hydrogen bonds with MPTL structure which stretch the structure of CA-modified MPTL in contrary to not modified MPTL [53]. However, the peaks are not shifted, what suggests that the CA modification is the physical modification.

Performed microbiological studies revealed that CA is relevant antimicrobial agent and works against the bacterial species such as E. coli, S. aureus, the main species responsible for wounds infections according to references [29, 54].

The microbiological tests showed that $3.5 \%$ of CA included into MPTLs is optimal dose to reach effective antimicrobial effect. Similar tests were performed by Sanla-Ead et al. [36] who reported CA antimicrobial activity after incorporation into cellulose-based packaging films. Gao et al. [55] presented an antibacterial activity of PVA films crosslinked by cinnamaldehyde, which were used at concentrations $0.5 \%$, $1 \%$, and $2 \%$. In this study, we found that CA-PU scaffolds tested via "agar-disk diffusion assay" showed antimicrobial activity against $S$. aureus and E. coli when the concentration of CA used for MPTL modification was $>3.5 \%$ (Table 1). For lower CA concentration $(0.5,1.0$, and $2.5 \%$, respectively), the antimicrobial effect of CA was not significant.

Moreover, the analysis of data presented in Table 1 suggested that the antimicrobial activity of CA-modified MPTL (3.5-5.0\%) seems to be weak. However, during the interpretation these results, it should be taken into account that CA has low water solubility [36]. In the result, the "speed" of diffusion of CA from CA-modified MPTL is low. In our opinion, in the wet environment of healing wound, this property is an advantage of CA-modified MPTL scaffolds. It results in long period of antimicrobial protection of wound during skin tissue regeneration. Moreover, the antimicrobial effect of CA is focused on the contact between surface of the wound dressing and damaged skin tissue. Therefore, the purpose of this study was to find the concentration of CA in CA-modified MPTL scaffold which allow ensuring antibacterial activity and good mechanical proportion of novel material potentially useful for wound dressing fabrication. In our opinion, this study revealed that the optimal concentration of CA in CA-modified MPTL scaffolds, which allows to fulfill both conditions which is $3.5 \%$. The mechanical properties of obtained unmodified and 
CA-modified MPTLs were only slightly changed. Thus, the mechanical characteristic of CA-modified MPTLs was suitable for biomedical applications of the scaffolds. It is due to the fact that $E$ for human back skin is between $0.21-3.29$ and $0.155 \mathrm{MPa}$ for human thoracic and abdominal skin [56]. The $\varepsilon b$ of the skin is 70-77\% [6]. The $E$ and $\varepsilon b$ of obtained CA-modified MPTLs are of $0.244 \mathrm{MPa}$ and $\sim 68 \%$. It is worth mentioning that along with a decrease in the scaffold elongation (it occurred as a result of CA modification), the brittleness increase. Thus, according to the Brostow et al. [14, 57-59], it may have an influence on the decrease in the material dimensional stability. In addition, obtained MPTLs were characterized by relevant morphology for epidermis regeneration. The CA-modified MPTLs porosity was $\sim 82 \%$, and pores sizes were in the range of $65-426 \mu \mathrm{m}$, what is the higher range than given in the references, where an ideal scaffold porosity for skin regeneration should be between 100 and $200 \mu \mathrm{m}$ [60] and the favorable porosity is about 90\% [60]. The CA modification revealed some morphology changes of the scaffolds. As described in the references, the most suitable contact angle for tissue regeneration is in the range of $45^{\circ}-76^{\circ}$. Obtained unmodified and CA-modified MPTLs had contact angle of $54^{\circ}$ and $66^{\circ}$, respectively. Thus, obtained scaffolds may be considered as suitable in terms of proper hydrophilicity of the material, which can be recognized as suitable surface for cells adhesion. The initial studies of unmodified and CA-modified MPTLs interactions with PBS showed that observed mass change after 1 month is significant (over 50\% for unmodified and 60\% for CA-modified MPTLs), and these materials may be considered as degradable materials in the fluids biomimicking natural biological environment. Additionally, modification of MPTLs with CA accelerated the degree of degradation rate. Thus, performed studies revealed that CA-modified MPTLs may be suitable candidates for regeneration of skin injuries and defects.

\section{Conclusion}

The main aim of this work was to obtain MPTLs modified with an antibacterial agent, which will improve the antibacterial effect of obtained scaffolds. To reach this aim the CA was used, which is not well known at the moment in the field of tissue engineering. CA possesses great antibacterial and antifungal properties. This work let to establish that the optimal concentration of CA solution for MPTL modification is $3.5 \%$. Achieved antibacterial effect at this CA concentration is suitable to treat wounds, what is in accordance with the literature: Dewi et al. [40] established that CA concentrations used in this work are in the suitable range to not to cause cytotoxic effect on cells and are safe for soft tissues. Investigations of mechanical properties and morphology indicated that CA reveals effect on these properties. On the other hand, contact angle has slightly increased due to the CA hydrophobic character. Observed mass change (over $50 \%$ for unmodified and over $60 \%$ for CAmodified MPTL) indicates that these materials may find a successful application as a biodegradable tissue scaffolds. According to the performed studies we assume that obtained CA-modified MPTLs may find an application as a functional antibacterial scaffolds for regeneration of injured and defected skin. 


\section{Compliance with ethical standards}

Conflict of interest The authors declare that they have no conflict of interest.

Open Access This article is distributed under the terms of the Creative Commons Attribution 4.0 International License (http://creativecommons.org/licenses/by/4.0/), which permits unrestricted use, distribution, and reproduction in any medium, provided you give appropriate credit to the original author(s) and the source, provide a link to the Creative Commons license, and indicate if changes were made.

\section{References}

1. Esteban-vives R, Young MT, Ziembicki J et al (2015) ScienceDirect Effects of wound dressings on cultured primary keratinocytes. Burns. https://doi.org/10.1016/j.burns.2015.06.016

2. Anjum S, Arora A, Alam MS, Gupta B (2016) Development of antimicrobial and scar preventive chitosan hydrogel wound dressings. Int J Pharm 508:92-101. https://doi.org/10.1016/j.ijpha rm.2016.05.013

3. Vowden K (2017) Wound dressings: principles and practice. Surgery 35:489-494. https://doi. org/10.1016/j.mpsur.2017.06.005

4. Koosehgol S, Ebrahimian-hosseinabadi M, Alizadeh M, Zamanian A (2017) Preparation and characterization of in situ chitosan/polyethylene glycol fumarate/thymol hydrogel as an effective wound dressing. Mater Sci Eng, C 79:66-75. https://doi.org/10.1016/j.msec.2017.05.001

5. Yari A, Yeganeh H, Bakhshi H (2012) Synthesis and evaluation of novel absorptive and antibacterial polyurethane membranes as wound dressing. J Mater Sci Mater Med. https://doi.org/10.1007/ s10856-012-4683-6

6. Bergamo R, Buzatto C, Alberto J, Maria Â (2017) Electrospun multilayer chitosan scaffolds as potential wound dressings for skin lesions. Eur Polym J 88:161-170. https://doi.org/10.1016/j.eurpo lymj.2017.01.021

7. Fan L, Yang H, Yang J et al (2016) Preparation and characterization of chitosan/gelatin/PVA hydrogel for wound dressings. Carbohydr Polym 146:427-434. https://doi.org/10.1016/j.carbp ol.2016.03.002

8. Agarwal T, Narayan R, Maji S, Behera S (2016) Gelatin/carboxymethyl chitosan based scaffolds for dermal tissue engineering applications. Int J Biol Macromol 93:1499-1506. https://doi. org/10.1016/j.ijbiomac.2016.04.028

9. Tavakoli J, Tang Y (2017) Honey/PVA hybrid wound dressings with controlled release of antibiotics: structural, physico-mechanical and in vitro biomedical studies. Mater Sci Eng, C 77:318-325. https://doi.org/10.1016/j.msec.2017.03.272

10. Ganesan P (2017) Natural and bio polymer curative films for wound dressing medical applications. Biochem Pharmacol 18:33-40. https://doi.org/10.1016/j.wndm.2017.07.002

11. Xie H, Chen X, Shen X et al (2017) Preparation of chitosan-collagen-alginate composite dressing and its promoting effects on wound healing. Int J Biol Macromol. https://doi.org/10.1016/j.ijbio mac.2017.08.142

12. Rieger KA, Schiffman JD (2014) Electrospinning an essential oil: cinnamaldehyde enhances the antimicrobial efficacy of chitosan/poly(ethylene oxide) nanofibers. Carbohydr Polym 113:561-568. https://doi.org/10.1016/j.carbpol.2014.06.075

13. Kamoun EA, Kenawy ES, Chen X (2017) A review on polymeric hydrogel membranes for wound dressing applications: PVA-based hydrogel dressings. J Adv Res 8:217-233. https://doi. org/10.1016/j.jare.2017.01.005

14. Witold Brostow HEH, Lobland HEH (2017) Materials: introduction and applications. Wiley, Hoboken

15. Chua AWC, Ma DR, Song IC et al (2008) In vitro evaluation of fibrin mat and Tegaderm ${ }^{\mathrm{TM}}$ wound dressing for the delivery of keratinocytes-implications of their use to treat burns. Burns 34:175180. https://doi.org/10.1016/j.burns.2007.07.009

16. Czemplik M, Kulma A, Szopa J (2013) The local treatment and available dressings designed for chronic wounds. J Am Acad Dermatol. https://doi.org/10.1016/j.jaad.2011.06.028 
17. Lin Y, Lee G, Chou C et al (2015) Stimulation of wound healing by PU/hydrogel composites containing fi broblast growth factor-2. J Mater Chem B Mater Biol Med 3:1931-1941. https://doi. org/10.1039/C4TB01638F

18. Oh S, Kim W, Kim S et al (2011) The preparation of polyurethane foam combined with pH-sensitive alginate/bentonite hydrogel for wound dressings. Fibers Polymers 12:159-165. https://oi. org/10.1007/s12221-011-0159-4

19. Manikandan A, Prasath M, Kumar S (2017) Formation of functional nano fi brous electrospun polyurethane and murivenna oil with improved haemocompatibility for wound healing. Polym Test 61:106-113. https://doi.org/10.1016/j.polymertesting.2017.05.008

20. Patel DK, Rana D, Aswal VK et al (2015) Influence of graphene on self-assembly of polyurethane and evaluation of its biomedical properties. Polymer (Guildf) 65:183-192. https://doi. org/10.1016/j.polymer.2015.03.076

21. Tsai M, Hung K, Hung S, Hsu S (2015) Evaluation of biodegradable elastic scaffolds made of anionic polyurethane for cartilage tissue engineering. Colloids Surf B Biointerfaces 125:34-44. https://doi.org/10.1016/j.colsurfb.2014.11.003

22. Mi H, Salick MR, Jing X et al (2013) Characterization of thermoplastic polyurethane/polylactic acid (TPU/PLA) tissue engineering scaffolds fabricated by microcellular injection molding. Mater Sci Eng, C 33:4767-4776. https://doi.org/10.1016/j.msec.2013.07.037

23. Janik H, Marzec M (2015) A review: fabrication of porous polyurethane scaffolds. Mater Sci Eng, C 48:586-591. https://doi.org/10.1016/j.msec.2014.12.037

24. Mi H, Jing X, Salick MR et al (2016) Carbon nanotube (CNT) and nano fi brillated cellulose (NFC) reinforcement effect on thermoplastic polyurethane (TPU) scaffolds fabricated via phase separation using dimethyl sulfoxide (DMSO) as solvent. J Mech Behav Biomed Mater 62:417427. https://doi.org/10.1016/j.jmbbm.2016.05.026

25. Gabriel LP, Amélia A, Macedo M et al (2017) Electrospun polyurethane membranes for tissue engineering applications. Mater Sci Eng, C 72:113-117. https://doi.org/10.1016/j. msec.2016.11.057

26. Hung K, Tseng C, Dai L, Hsu S (2016) Biomaterials water-based polyurethane 3D printed scaffolds with controlled release function for customized cartilage tissue engineering. Biomaterials 83:156-168. https://doi.org/10.1016/j.biomaterials.2016.01.019

27. Benítez JM, Montáns FJ (2017) The mechanical behavior of skin: structures and models for the finite element analysis. Comput Struct 190:75-107. https://doi.org/10.1016/j.comps truc.2017.05.003

28. Kucińska-Lipka J, Gubanska I, Skwarska A (2017) Microporous polyurethane thin layer as a promising scaffold for tissue engineering. Polymers (Basel) 9:277. https://doi.org/10.3390/polym 9070277

29. Shen S, Zhang T, Yuan Y et al (2015) Effects of cinnamaldehyde on Escherichia coli and Staphylococcus aureus membrane. Food Control 47:196-202. https://doi.org/10.1016/j.foodc ont.2014.07.003

30. Al-Bayati FA, Muthanna MJ (2009) Isolation, identification, and purification of cinnamaldehyde from cinnamomum zeylanicum bark oil. An antibacterial study. Pharm Biol. 47(1): 61-66. https ://doi.org/10.1080/13880200802430607

31. Shreaz S, Wani WA, Behbehani JM et al (2016) Fitoterapia Cinnamaldehyde and its derivatives, a novel class of antifungal agents. Fitoterapia 112:116-131. https://doi.org/10.1016/j.fitot e.2016.05.016

32. Kwon YS, Lee SH, Hwang YC et al (2017) Behaviour of human dental pulp cells cultured in a collagen hydrogel scaffold cross-linked with cinnamaldehyde. Int Endod J. https://doi. org/10.1111/iej.12592

33. Nostro A, Scaffaro R, Arrigo MD, Botta L, Filocamo A, Marino A (2012) Study on carvacrol and cinnamaldehyde polymeric films: mechanical properties, release kinetics and antibacterial and antibiofilm activities. Appl Microb Cell Physiol. https://doi.org/10.1007/s00253-012-4091-3

34. Song Y-R, Choi M-S, Choi G-W, Park I-K, Oh C-S (2016) Antibacterial activity of cinnamaldehyde and estragole extracted from plant essential oils against pseudomonas syringae pv. actinidiae causing bacterial canker disease in kiwifruit. Plant Pathol J 32(4):363-370. https://doi. org/10.5423/PPJ.NT.01.2016.0006

35. Bauchan G, Lo YM (2014) Antibacterial activity of cinnamaldehyde and sporan against Escherichia coli O157:H7 and Salmonella. J Food Process Preserv 38:749-757. https://doi.org/10.1111/ jfpp. 12026 
36. Sanla-Ead N, Jangchud A, Chonhenchob V, Suppakul P (2012) Antimicrobial activity of cinnamaldehyde and eugenol and their activity after incorporation into cellulose-based packaging films. Packag Technol Sci 25:7-17. https://doi.org/10.1002/pts.952

37. Nazzaro F, Fratianni F, De Martino L, Coppola R, De Feo V (2013) Effect of essential oils on pathogenic bacteria. Pharmaceuticals 6:1451-1474. https://doi.org/10.3390/ph6121451

38. Zhang Hongmei, Zhou Wenyuan, Zhang Wenyan, Yang Anlin, Liu Yanlan, Jiang Yan, Shaosong Huang JS (2014) Inhibitory effects of citral, cinnamaldehyde, and tea polyphenols on mixed biofilm formation by foodborne Staphylococcus aureus and Salmonella enteritidis. J Food Prot 77:927-933. https://doi.org/10.4315/0362-028X.JFP-13-497

39. Jia P, Xue YJ, Duan XJ, Shao SH (2011) Effect of cinnamaldehyde on biofilm formation and sarA expression by methicillin-resistant Staphylococcus aureus. Lett Appl Microbiol. https://doi. org/10.1111/j.1472-765X.2011.03122.x

40. Dewi AH, Ana ID, Jansen J (2016) Calcium carbonate hydrogel construct with cynnamaldehyde incorporated to control inflammation during surgical procedure. J Biomed Mater Res, Part A 104:768-774. https://doi.org/10.1002/jbm.a.35571

41. Nascimento GGF, Locatelli J, Freitas PC, Silva GL (2000) Antibacterial activity of plant extracts and phytochemicals on antibiotic-resistant bacteria. Braz J Microbiol 31:247-256. https://doi. org/10.1590/S1517-83822000000400003

42. Brostow W, Brumbley S, Gahutishvili M, Hnatchuk N (2016) Arsenic antibacterial polymer composites based on poly(vinyl chloride). Macromol Symp 365:258-262. https://doi.org/10.1002/ masy.201650002

43. Barbakadze K, Brostow W, Datashvili T et al (2018) Antibiocorrosive epoxy-based coatings with low friction and high scratch resistance. Wear 394-395:228-235. https://doi.org/10.1016/j. wear.2017.08.006

44. Kucinska-Lipka J, Gubanska I, Strankowski M et al (2017) Synthesis and characterization of cycloaliphatic hydrophilic polyurethanes, modified with L-ascorbic acid, as materials for soft tissue regeneration. Mater Sci Eng, C 75:671-681. https://doi.org/10.1016/j.msec.2017.02.052

45. Kucińska-Lipka J, Gubanska I, Korchynskyi O et al (2017) The influence of calcium glycerophosphate (GPCa) modifier on physicochemical, mechanical and biological performance of polyurethanes applicable as biomaterials for bone tissue scaffolds fabrication. Polymers 9(8):329. https://doi.org/10.3390/polym9080329

46. Špirková Milena, Poręba Rafał, Pavličević Jelena, Kobera Libor, Josef Baldrian MP (2012) Aliphatic polycarbonate-based polyurethane elastomers and nanocomposites. I. The influence of hard-segment content and macrodiol-constitution on bottom-up self-assembly. J Appl Polym Sci 126:1016-1030

47. Yilgor I, Yilgor E, Guler IG et al (2006) FTIR investigation of the influence of diisocyanate symmetry on the morphology development in model segmented polyurethanes. Polymer (Guildf) 47:4105-4114. https://doi.org/10.1016/j.polymer.2006.02.027

48. Tian Y, Zhu Y, Bashari M et al (2013) Identification and releasing characteristics of high-amylose corn starch-cinnamaldehyde inclusion complex prepared using ultrasound treatment. Carbohydr Polym 91:586-589. https://doi.org/10.1016/j.carbpol.2012.09.008

49. Manukumar HM, Umesha S (2017) Photocrosslinker technology: an antimicrobial efficacy of cinnamaldehyde cross-linked low-density polyethylene (Cin-C-LDPE) as a novel food wrapper. Food Res Int 102:144-155. https://doi.org/10.1016/j.foodres.2017.09.095

50. Yang Z, Chai K, Ji H (2011) Selective inclusion and separation of cinnamaldehyde and benzaldehyde by insoluble $\beta$-cyclodextrin polymer. Sep Purif Technol 80:209-216. https://doi. org/10.1016/j.seppur.2011.04.017

51. Chen H, Hu X, Chen E et al (2016) Preparation, characterization, and properties of chitosan films with cinnamaldehyde nanoemulsions. Food Hydrocoll 61:662-671. https://doi.org/10.1016/j. foodhyd.2016.06.034

52. Smith BC (2016) Group wavenumbers and an introduction to the spectroscopy of benzene rings. Spectroscopy 31:34-37

53. Cristina A, Souza D, Dias AMA et al (2014) Impregnation of cinnamaldehyde into cassava starch biocomposite films using supercritical fluid technology for the development of food active packaging. Carbohydr Polym 102:830-837. https://doi.org/10.1016/j.carbpol.2013.10.082

54. Otoni CG, De Moura MR, Aouada FA et al (2014) Food hydrocolloids antimicrobial and physical-mechanical properties of pectin/papaya puree/cinnamaldehyde nanoemulsion edible composite films. Food Hydrocoll 41:188-194. https://doi.org/10.1016/j.foodhyd.2014.04.013 
55. Gao H (2017) Characteristics of poly vinyl alcohol films crosslinked by cinnamaldehyde with improved transparency and water resistance. J Appl Polym Sci 24:1-8. https://doi.org/10.1002/ app.45324

56. Then C, Stassen B, Depta K, Silber G (2017) New methodology for mechanical characterization of human superficial facial tissue anisotropic behaviour in vivo. J Mech Behav Biomed Mater 71:68-79. https://doi.org/10.1016/j.jmbbm.2017.02.022

57. Brostow W, Hagg Lobland HE, Narkis M (2006) Sliding wear, viscoelasticity, and brittleness of polymers. J Mater Res 21:2422-2428. https://doi.org/10.1557/jmr.2006.0300

58. Brostow W, Lobland HEH, Narkis M (2011) The concept of materials brittleness and its applications. Polym Bull 67:1697-1707. https://doi.org/10.1007/s00289-011-0573-1

59. Brostow W, Hagg Lobland HE (2010) Brittleness of materials: implications for composites and a relation to impact strength. J Mater Sci 45:242-250. https://doi.org/10.1007/s10853-009-3926-5

60. Ma L, Gao C, Mao Z et al (2003) Collagen/chitosan porous scaffolds with improved biostability for skin tissue engineering. Biomaterials 24:4833-4841. https://doi.org/10.1016/S0142-9612(03)00374 $-0$ 